\title{
$-\infty$ \\ Desenvolvimento de Jogos Educativos Digitais utilizando a Ferramenta de Autoria Multimídia: um estudo de caso com o ToolBook Instructor
}

\author{
Gilse Antoninha Morgental Falkembach - UNIFRA e ULBRA - Santa Maria - \\ gilsemf@terra.com.br \\ Marlise Geller - ULBRA - Canoas - m.geller@terra.com.br \\ Sidnei Renato Silveira - UniRitter e Facensa - sidnei@uniritter.com.br
}

\section{Resumo}

O presente artigo apresenta um estudo teórico-prático, buscando destacar concepções subjacentes de jogos educativos e discutindo a implementação de jogos educativos digitais através da utilização de ferramentas de autoria multimídia, em especial o ToolBook Instructor.

Palavras-Chave: Jogos Educativos Digitais, Ferramentas de Autoria Multimídia

\section{Digital Educational Games Development: a case study applying ToolBook Instructor}

\begin{abstract}
This paper presents a theorical-practice study, involving digital educational games development by multimedia authoring tools. Also presents a digital educacional games development in ToolBook Instructor.
\end{abstract}

Key-Words: Digital Educational Games, Multimedia Authoring Tools.

\section{Introdução}

Os jogos educativos digitais possibilitam a criação de ambientes de aprendizagem atraentes e gratificantes, constituindo-se num recurso poderoso de estímulo para o desenvolvimento integral do aluno, permitindo o desenvolvimento de inúmeras habilidades.

Dentre as inúmeras possibilidades para o desenvolvimento de software educacional, mais especificamente os jogos educativos digitais, a multimídia é uma das áreas que possibilita que este tipo de software desperte um maior interesse, auxiliando o aluno na realização de tarefas que exigem a manipulação de informações complexas, diminuindo a sobrecarga cognitiva, além de fornecer flexibilidade ao usuário, para que este possa definir e organizar relações entre as idéias necessárias para alcançar seus objetivos. A multimídia permite a utilização de diversos meios de comunicação. Utilizando-se ferramentas de autoria multimídia é possível elaborar desde courseware até jogos educativos digitais. 
Neste sentido, este artigo apresenta um estudo teórico-prático, buscando destacar concepções subjacentes de jogos educativos e discutindo a implementação de jogos educativos digitais através da utilização de ferramentas de autoria multimídia, mais especificamente a ferramenta ToolBook Instructor.

\section{Jogos Educativos}

Os jogos educativos baseiam-se no interesse pelo lúdico que independe da faixa etária. Considerando-se este aspecto, os jogos podem promover ambientes de aprendizagem atraentes e gratificantes, constituindo-se num recurso poderoso de estímulo para o desenvolvimento integral do aluno. Segundo Rizzo (1988), os jogos desenvolvem a atenção, disciplina, autocontrole, respeito a regras e habilidades perceptivas e motoras relativas a cada tipo de jogo oferecido. Podem ser jogados de forma individual ou coletiva, sempre com a presença do educador para mediar o processo, observar e avaliar o nível de desenvolvimento dos alunos, diagnosticando as dificuldades individuais.

Conforme Negrine (1994, p. 9), “jogo se origina do vocábulo latino 'iocus', que significa diversão, brincadeira. Em alguns dicionários aparece como sendo a 'atividade lúdica com um fim em si mesma, embora ocasionalmente possa se realizar por motivo extrínseco".

Segundo diversos autores da área de Educação, dos quais citam-se Lebovici \& Deatkine (1985) e Rodrigues (1992), o ato de jogar é uma atividade muito importante na vida da criança. Ela joga por entretenimento e também porque o jogo representa esforço e conquista. A maior parte do tempo na infância é dedicada ao jogo. É uma necessidade vital, a preparação para a vida, possibilitando o equilíbrio entre o mundo externo e o interno, canalizando as energias das crianças e transformando em prazer suas angústias.

O jogo, dadas suas potencialidades, é uma via possível para estimular ou reforçar tanto as situações familiares como comunitárias, como de estimulação de competências cognitivas. O jogo e a atividade de jogar devem tornar-se uma alternativa de realização pessoal que, além de possibilitar a expressão de sentimentos e emoções, propiciam a aprendizagem de comportamentos adequados e adaptativos, aumentando a possibilidade de êxito na aprendizagem (Kotliarenco, 1997). Chapman \& Martin (1995) colocam que os jogos oportunizam a descoberta de soluções para os mais variados problemas, através do estabelecimento de estratégias e implicações, encorajando os estudantes a resolvê-los.

\subsection{A Influência dos Jogos no Desenvolvimento da Criança}

Segundo Grossi (s.d., p. 86), "O jogo é uma atividade rica e de grande efeito que responde às necessidades lúdicas, intelectuais e afetivas, estimulando a vida social e representando, assim, importante contribuição na aprendizagem". Santos (1998) afirma que as atividades lúdicas podem contribuir significativamente para o processo de construção do conhecimento da criança e que o jogo é uma fonte de prazer e descoberta.

Vygotsky afirma que a influência do brinquedo no desenvolvimento da criança é enorme. Através do brinquedo a criança aprende a agir numa esfera cognitivista, sendo livre para determinar suas próprias ações. O brinquedo desenvolve a curiosidade, a 
iniciativa e a autoconfiança, proporcionando o desenvolvimento da linguagem, do pensamento e da concentração (Vygotsky, 1989). Baquero (1998, p. 101) diz que “...Vygotsky destaca o caráter central do brinquedo na vida da criança, (...) indo além das funções de exercício funcional, de seu valor expressivo, de seu caráter elaborativo, etc. Em segundo lugar, o brinquedo parece estar caracterizado (...) como uma das maneiras da criança participar na cultura, é sua atividade cultural típica, como o será em seguida, quando adulto, o trabalho".

Segundo Leif \& Brunelle (1978, p. 114), "Desde Claparède e Dewey, Wallon e Piaget, está bastante claro que a atividade lúdica é o berço obrigatório das atividades intelectuais e sociais superiores". Uma das atividades superiores que nasce do jogo é o trabalho, sem o que nem a arte, a ciência, nem mesmo o esporte poderiam se desenvolver. Rizzi (1994) diz que jogando a criança forma suas atitudes sociais tais como: respeito mútuo, solidariedade, cooperação, obediência às regras, senso de responsabilidade, iniciativa pessoal e grupal. Segundo Clunie (et al, 1996), a função do jogo é "treinar o sujeito para a convivência social no mundo regido por leis que precisam ser conhecidas, simulando situações que ele vivencia, onde pode extrapolar o concreto (...). Um único jogo pode desenvolver e aperfeiçoar diversos tipos de conceitos, sendo aplicável em diversas áreas do conhecimento".

Piaget afirma que a importância do jogo está na satisfação das necessidades das crianças quanto à assimilação da realidade à sua própria vontade. Estas necessidades originam-se da estranheza de coisas que as crianças não compreendem no mundo dos adultos, como regras, por exemplo: hora de dormir, comer, tomar banho, não mexer em certos objetos, entre outras. O jogo tem uma relação estreita com a construção da inteligência e possui uma efetiva influência como instrumento incentivador e motivador no processo de aprendizagem.

Segundo Negrine (1994, p. 18), “...Piaget entende que a inteligência é uma forma de adaptação ao meio, e o jogo é basicamente uma forma de relação da criança com o contexto no qual ela está inserida; neste sentido, adverte que a criança elabora e desenvolve suas estruturas mentais através das diversas atividades lúdicas". Para Piaget, conforme Brenelli (1996, p. 21), “...por meio de atividade lúdica, a criança assimila ou interpreta a realidade própria, atribuindo, então, ao jogo um valor educacional muito grande. Neste sentido, propõe-se que a escola possibilite um instrumental à criança, para que, por meio de jogos, ela assimile as realidades intelectuais, a fim de que estas mesmas realidades não permaneçam exteriores à sua inteligência”. Baseando-se nestas afirmações, pode-se verificar a importância que Piaget atribui às atividades lúdicas, reforçando a idéia de que os educadores devem utilizá-las no contexto educacional.

\section{Jogos Educativos Digitais}

Os jogos educativos digitais são elaborados para divertir os alunos e potencializar a aprendizagem de conceitos, conteúdos e habilidades embutidas no jogo. Um jogo educativo digital pode propiciar ao aluno um ambiente de aprendizagem rico e complexo. Estes jogos podem ser denominados micromundos, porque fornecem um mundo imaginário a ser explorado e no qual os alunos podem aprender.

As características que tornaram os jogos educativos digitais intrinsecamente motivadores são o desafio, a fantasia e a curiosidade. Os jogos podem fornecer alguns 
resultados educativos não previstos e que são tão importantes quanto os previamente determinados. Podem oferecer oportunidades para o aluno usar lógica, raciocínio e habilidades de organização para resolver problemas de maneira mais interessante do que seriam expostos em um exercício comum. Um jogo simples pode ensinar várias habilidades e conceitos, propiciando o desenvolvimento de novas habilidades cognitivas.

Segundo resultados de uma pesquisa realizada sobre a utilização de jogos educativos digitais (Geller \& Silveira, 1998), os professores pesquisados consideram que a utilização destes jogos é vantajosa para o processo de ensino e aprendizagem, justificando que os mesmos servem como estímulo e reforço à motivação, reforçam os conteúdos estudados, despertam o interesse dos alunos, desenvolvem o raciocínio lógico, atraem os alunos, potencializam a aprendizagem, possibilitam a construção do conhecimento de forma prazerosa e propiciam uma forma diferenciada de aprendizagem.

Stahl (1991) e Bongiolo (1998) relacionam características importantes que devem estar presentes em um jogo educativo digital, das quais destacam-se as seguintes:

○ as instruções do jogo devem estar claras para os participantes e os objetivos do mesmo devem ser compreendidos pelos alunos;

- o jogo deve atrair e manter o interesse e o entusiasmo;

- o jogo deve explorar efeitos auditivos e visuais, para manter a curiosidade e a fantasia e facilitar o alcance do objetivo educacional proposto;

- explorar a competição;

○ permitir ao jogador controlar a interação e a continuação do jogo, o nível de dificuldade desejado, a taxa de avanço e a possibilidade de repetir segmentos;

- deve oferecer reforço positivo nos momentos adequados;

- incorporar o desafio, através da utilização de diferentes níveis para solucionar um determinado problema, pontuação, velocidade de resposta, feedback do progresso, entre outros aspectos;

- deve manter os alunos informados do nível de seu desempenho durante o jogo, fornecendo resumos do desempenho global ao final;

- utilizar mecanismos para corrigir possíveis erros dos alunos e melhorar o desempenho dos mesmos;

○ fornecer instruções inequívocas, exceto quando a descoberta de regras for parte integrante do jogo;

- propiciar um ambiente rico e complexo para resolução de problemas, através da aplicação de regras lógicas, da experimentação de hipóteses e antecipação de resultados e planejamento de estratégias.

Franciosi (citado por Bongiolo, 1998) coloca que, além das características apresentadas anteriormente, um jogo educativo digital precisa observar alguns requisitos de qualidade didático-pedagógica e também de qualidade técnica, tais como:

- requisitos de qualidade didático-pedagógica: objetivos bem definidos, encadeamento lógico do conteúdo, adequação do vocabulário, possibilidade de formação de conceitos, ortografia e gramática corretas, feedback apropriado, clareza e concisão dos 
textos apresentados, possibilidade de acesso direto a diferentes níveis do programa e possibilidade do professor interagir com o sistema, incluindo, excluindo ou alterando o conteúdo proposto;

- requisitos de qualidade técnica: execução rápida e sem erros, resistência a respostas inadequadas, interface amigável, tempo suficiente de exibição das telas, possibilidade de acesso à ajuda, possibilidade de trabalho interativo, possibilidade de controle do usuário sobre a sequiência de execução do jogo, possibilidade de correção das respostas, possibilidade de sair do sistema a qualquer momento e uso de telas com diagramação seguindo um modelo único de organização.

\section{Ferramentas de Autoria Multimídia}

A utilização de ferramentas de autoria multimídia possibilita a construção de software com recursos de imagens, textos, vídeos e sons, entre outros, sem que haja a necessidade do desenvolvedor aprender a programar numa linguagem de programação específica. A maioria das ferramentas de autoria multimídia possui facilidades para incorporação de diversas mídias e, muitas delas, não necessitam de código de programação, tais como o Visual Class e o Everest, por exemplo. Algumas possuem linguagens de programação embutidas, como é o caso do Macromedia Director (que possui a linguagem Lingo) e o Multimedia ToolBook (que utiliza a linguagem OpenScript). A diferença na utilização destas ferramentas é que, as que possuem uma linguagem de programação embutida, possibilitam uma maior liberdade ao desenvolvedor e, conseqüentemente, maiores recursos (Silveira, 1999).

O desenvolvimento de software educacional, tais como os jogos educativos digitais, é uma das áreas onde as ferramentas de autoria têm maior aplicação. As ferramentas de autoria oferecem um ambiente integrado para a combinação do conteúdo e das funções do software desenvolvido. Estas ferramentas fornecem a estrutura necessária para a organização e edição dos elementos de um software multimídia, incluindo gráficos, desenhos, animações, sons e vídeos. São utilizadas para o desenvolvimento da interface do software, visando estimular a interatividade, agrupando os elementos da multimídia num projeto coeso. As ferramentas de autoria mais elaboradas são os sistemas de autoria. Estes sistemas permitem, além das possibilidades de criar, editar e importar vários tipos de mídias, o desenvolvimento de código de programação, para responder a entradas do usuário.

\section{Instructor}

\section{Implementação de Jogos Educativos Digitais utilizando o ToolBook}

A ferramenta de autoria multimídia ToolBook Instructor, desenvolvida pela empresa Click2learn, é uma ferramenta de desenvolvimento profissional, constituindose num sistema de autoria. O ToolBook permite a construção de aplicativos hipermídia, unindo os recursos de hipertexto e multimídia. Inicialmente, foi projetada para o desenvolvimento de livros eletrônicos, mas com o avanço da tecnologia, esta ferramenta tornou-se muito mais poderosa, principalmente pelo fato de possuir uma linguagem de programação própria, que é o OpenScript. Esta ferramenta, apesar de possuir diversos recursos, é de fácil manuseio. Através da mesma, pode-se adicionar arquivos de áudio, vídeo, animações e textos. 
As possibilidades para a construção da interface do jogo são inúmeras, visto que o ToolBook permite desde a importação de imagens em diversos formatos, até a construção de desenhos utilizando as barras de ferramentas. A construção da interface dependerá da habilidade do desenvolvedor do jogo.

Com relação à programação, a linguagem OpenScript é de fácil aprendizado. $\mathrm{O}$ paradigma de programação é o de orientação a eventos, ou seja, os códigos de programação são executados em resposta à ocorrência de eventos tais como o clique com o botão esquerdo do mouse, o clique com o botão direito, a digitação de alguma informação via teclado e/ou a entrada numa nova tela da aplicação. O exemplo abaixo demonstra um trecho de código em OpenScript, que permite a exibição de uma mensagem quando o usuário clicar com botão esquerdo do mouse sobre um determinado objeto da interface.

$$
\begin{aligned}
& \text { to handle buttonclick } \\
& \text { request "Mensagem" } \\
& \text { end }
\end{aligned}
$$

A linguagem OpenScript possui comandos específicos para manipulação de mídias tais como vídeos e sons, através de comandos do tipo multimídia (MM MultiMedia). Além disso, por tratar-se de uma ferramenta de construção de hipertextos, possui recursos para a criação de hyperlinks, que permitem a ligação das diversas partes da aplicação e/ou a ligação com sites da web.

A Figura 1 apresenta a tela inicial de um software educacional desenvolvido utilizando-se a ferramenta ToolBook. Este software constitui-se num ambiente lúdico, contendo inúmeras atividades relacionadas à alfabetização. Visto que o software foi desenvolvido para crianças da pré-escola, além dos recursos visuais, todas as instruções dos jogos e atividades criadas são apresentadas oralmente, através da inclusão de diversos arquivos de som.

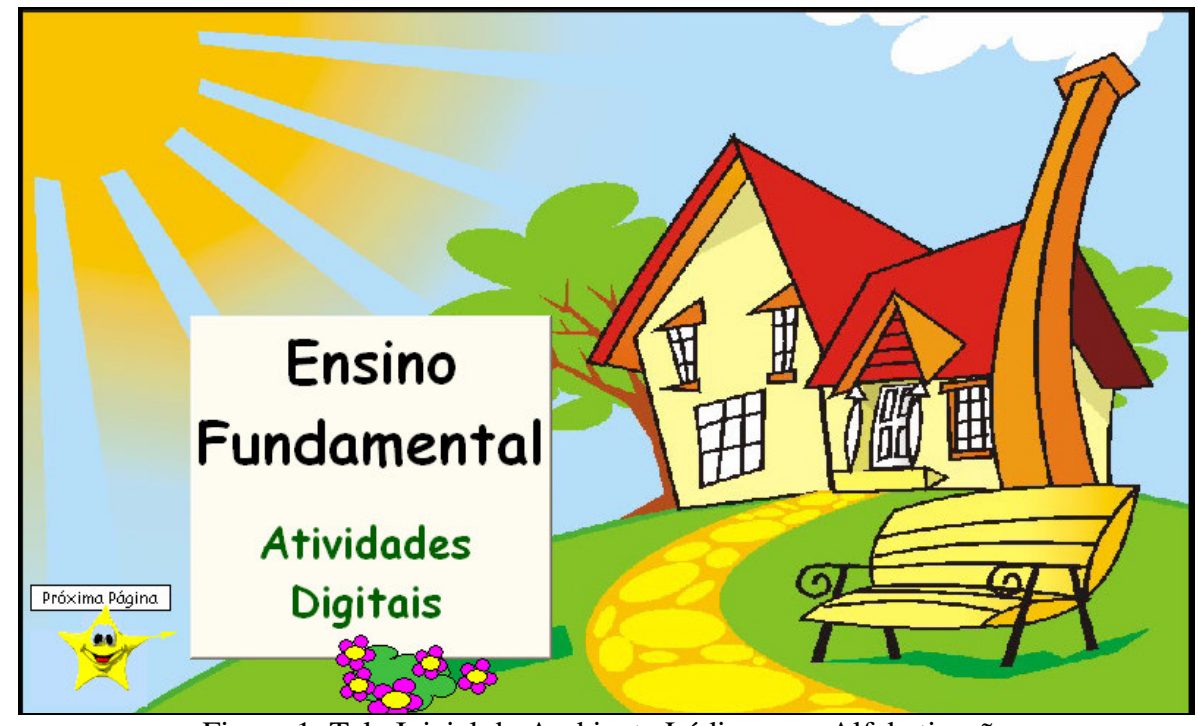

Figura 1: Tela Inicial do Ambiente Lúdico para Alfabetização

A Figura 2 apresenta uma das atividades disponibilizadas no ambiente lúdico proposto, que envolve a operação de ligar figuras. Os recursos de multimídia 
apresentados (figuras e sons) podem ser criados e/ou importados pelo ToolBook. Em todas as telas do jogo desenvolvido existem botões (em forma de estrelas) que permitem a navegação pelo ambiente.

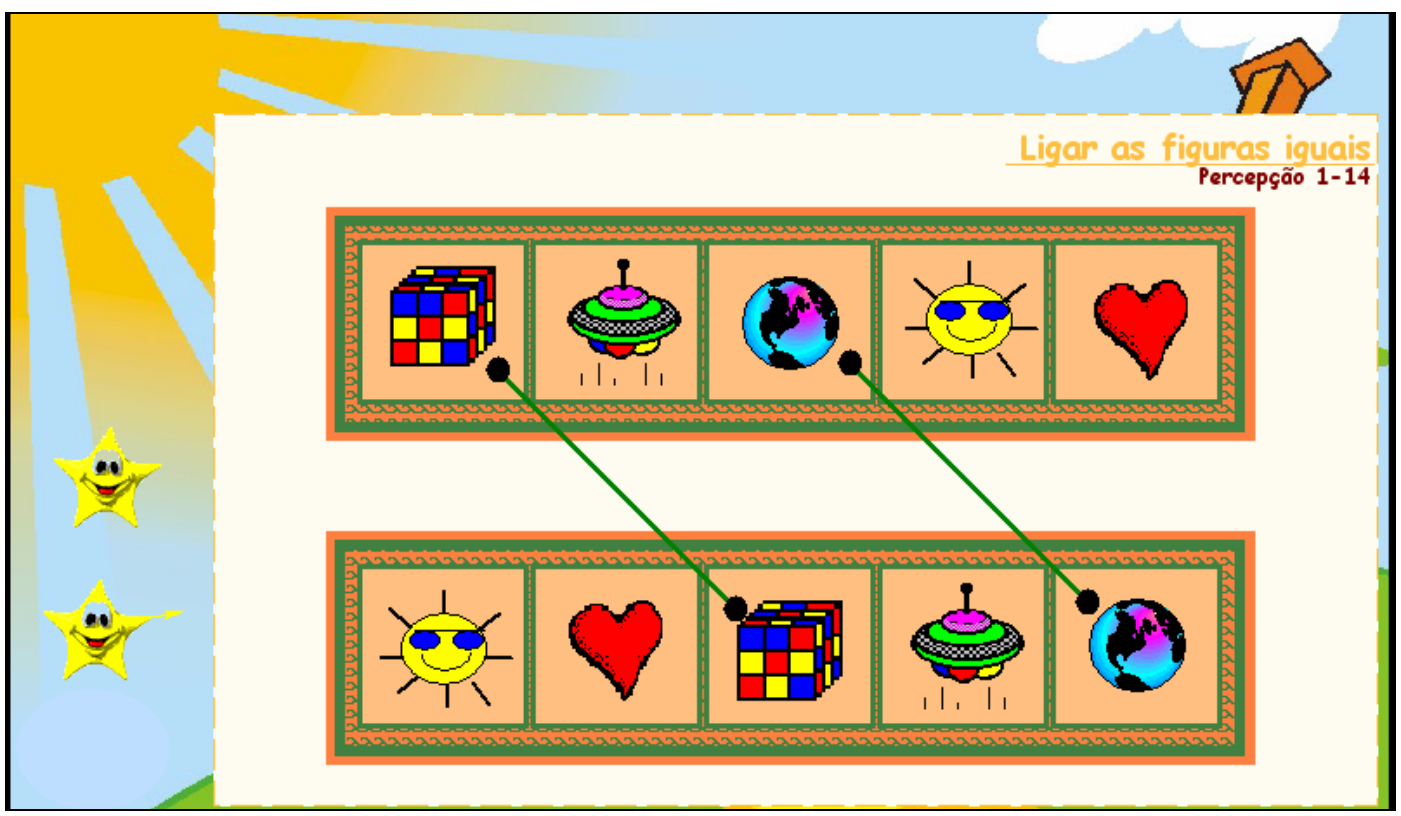

Figura 2: Atividade de Ligar Figuras

Na Figura 3 apresenta-se uma atividade de alfabetização, dentro do mesmo jogo digital demonstrado, voltada a um público de maior faixa etária, visto que é necessário digitar as palavras, ou seja, as crianças já precisam ter um maior domínio da escrita. Esta atividade constitui-se num jogo de palavras cruzadas.

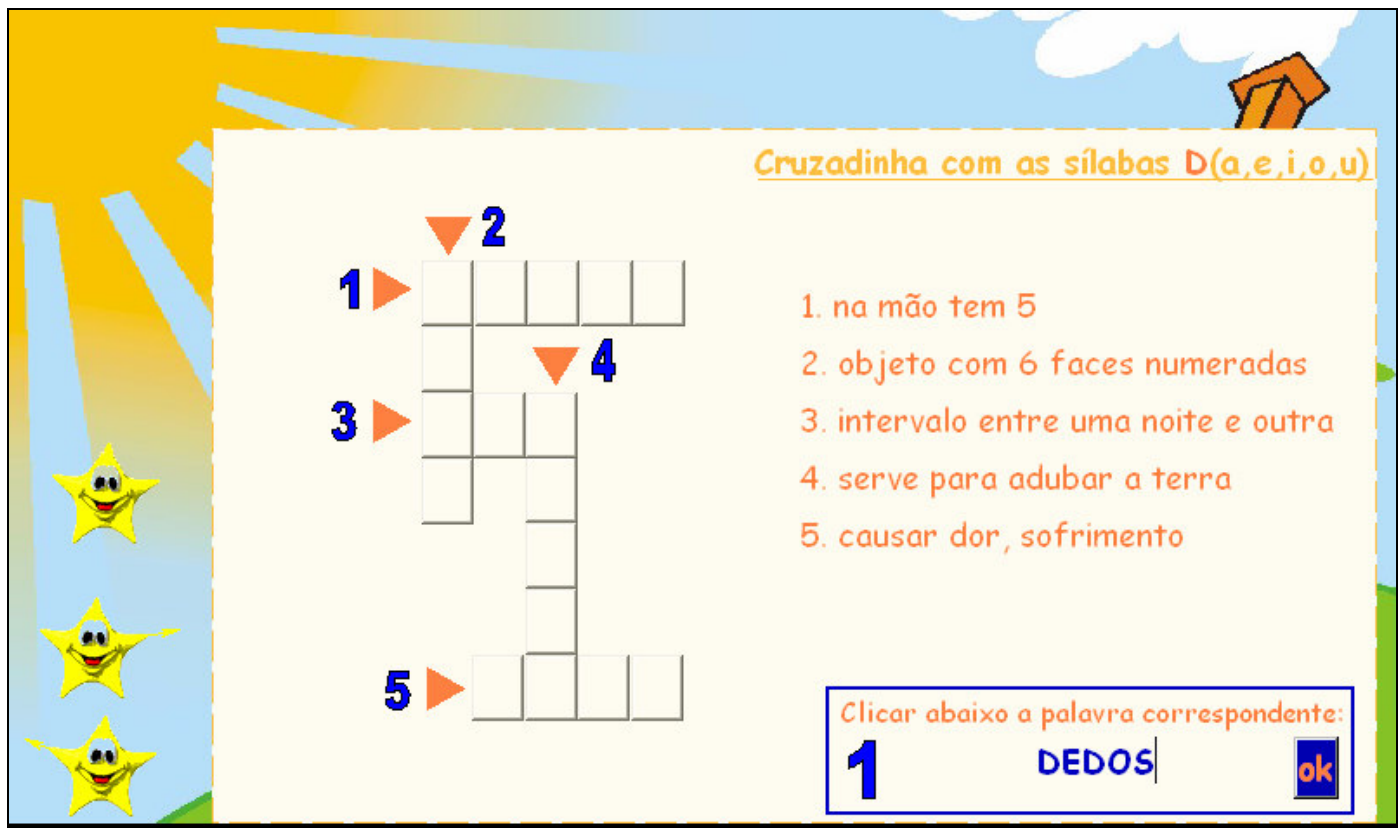

Figura 3: Jogo de Palavras Cruzadas

Na Figura 4 apresenta-se uma atividade que envolve a fase silábica. Nesta atividade a criança deve digitar a $1^{\text {a }}$ sílaba correspondente à figura apresentada. 


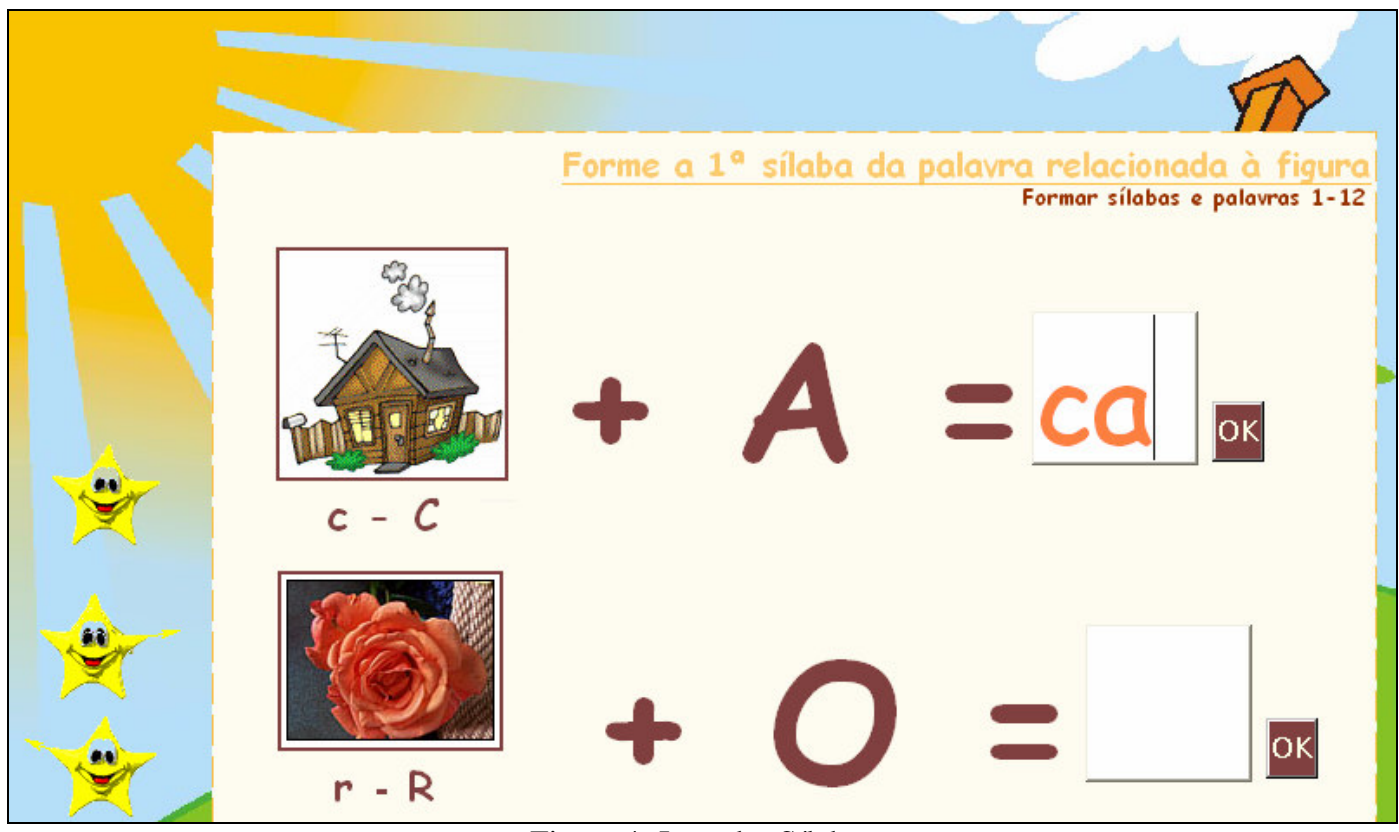

Figura 4: Jogo das Sílabas

Com os recursos para manipulação de itens em multimídia fornecidos pelo ToolBook Instructor, o desenvolvimento de jogos educativos digitais torna-se mais fácil e rápido, ao contrário do que seria utilizando-se uma linguagem de programação tradicional. O ambiente possibilita a integração facilitada das diversas mídias, permitindo que sejam criados ambientes com interfaces bastante atrativas. Além disso, a existência da linguagem OpenScript, que possui recursos específicos para possibilitar a apresentação e integração de diversas mídias, tais como vídeos e sons, permite o aprimoramento da interatividade necessária para os jogos educativos digitais despertarem o interesse das crianças.

\section{Considerações Finais}

O desenvolvimento de jogos educativos digitais proporciona que a atividade de jogar, que é inerente à criança, possa ser utilizada como um importante recurso educacional e motivacional, permitindo que as habilidades e conteúdos embutidos no jogo sejam potencializados no processo de ensino e aprendizagem.

A utilização de ferramentas de autoria multimídia, como é o caso do ToolBook Instructor, facilita o desenvolvimento de software educacional com recursos de multimídia, permitindo que equipes interdisciplinares possam desenvolver jogos educativos atrativos. Estas equipes podem ser formadas por profissionais de diversas áreas, envolvendo designers, educadores e informatas, possibilitando $\mathrm{o}$ desenvolvimento de jogos educativos digitais tão elaborados quanto os jogos comerciais existentes atualmente, que não possuem uma função educacional ou não foram projetados com este fim.

Desta forma, agregar os jogos digitais no processo educacional pode ampliar um universo complexo de significados, centrado no lúdico, promovendo a construção de conhecimento do aluno respeitando seu ritmo de aprendizagem, agregando novas 
informações e principalmente, resgatando o prazer em aprender que é fundamental para o processo de ensino e aprendizagem.

\section{Referências}

BAQUERO, Ricardo. A Zona de Desenvolvimento Proximal e a Análise das Práticas Educativas. In: Vygotsky e a Aprendizagem Escolar. Porto Alegre: Artes Médicas, 1998. p. 97-116.

BONGIOLO, Cyntia Elvira Franco et al. Subindo e Escorregando: jogo para introdução do conceito de adição de números inteiros. In: CONGRESSO DA REDE IBEROAMETICANA DE INFORMÁTICA NA EDUCAÇÃO, 4., 1998, Actas... Brasília: Universidade de Brasília, 1998.

BRENELli, Rosely Palermo. O Jogo como Espaço para Pensar: a construção de noções lógicas e aritméticas. Campinas, São Paulo: Papirus, 1996.

CHAPMAN, G. M.; MARTIN, J. F. Computerized Business Games in Engineering Education. Computers \& Education, Oxford, v. 25, n. 1/2, p. 67-73, 1995.

CLUNIE, Gisela et al. ESCOLA: Meta-ambiente de aprendizagem baseado em hipertecnologias. In: CONGRESSO DA REDE IBEROAMERICANA DE INFORMÁTICA NA EDUCAÇÃO, 3., 1996, Colômbia, Barranquilla. Anais... [s.1.: s.n.], 1996.

GELLER, Marlise; SILVEIRA, Sidnei Renato. Estudo e Análise de Jogos Educativos Computadorizados. Relatório de Pesquisa. Canoas: ULBRA, 1998.

GROSSI, Esther Pillar (Org.). Escolas Infantis: leitura e escrita. Erechim: Edelbra, 199 ?.

KOTLIARENCO, Maria Angélica. El Juego como Posibilidad de Refuerzo a la Resiliencia. In: Brinquedoteca: o lúdico em diferentes contextos. Petrópolis, Rio de Janeiro: Vozes, 1997.

LEBOVICI, S.; DIATKINE, R. Significado e Função do Brinquedo na Criança. Porto Alegre: Artes Médicas, 1985.

LEIF, Joseph; BRUNELLE, Lucien. O Jogo pelo Jogo: a atividade lúdica na educação de crianças e adolescentes. Rio de Janeiro: Zahar, 1978.

NEGRINE, Airton. Aprendizagem e Desenvolvimento Infantil: simbolismo e jogo. Porto Alegre: PRODIL, 1994. v. 1.

RIZZI, Leonor et al. Atividades Lúdicas na Educação da Criança. São Paulo, 1994. Série Educação.

RIZZO, Gilda. O Método Natural de Alfabetização. In: Alfabetização Natural. Rio de Janeiro: Francisco Alves, 1988. p. 33-129. 
RODRIGUES, Maria. O Desenvolvimento do Pré-Escolar e o Jogo. São Paulo: Ícone, 1992.

SANTOS, Carlos Antonio. Jogos e Atividades Lúdicas na Alfabetização. Rio de Janeiro: Sprint, 1998.

SILVEIRA, Sidnei Renato. Estudo e Construção de uma Ferramenta de Autoria Multimídia para a Elaboração de Jogos Educativos. Porto Alegre: PPGC/UFRGS, 1999. Dissertação de Mestrado.

STHAL, Marimar M. Ambientes e Ensino-Aprendizagem Computadorizados: da sala de aula convencional ao mundo da fantasia. Rio de Janeiro: COPPE-UFRJ, 1991.

VYGOTSKY, L. S. O Papel do Brinquedo no Desenvolvimento. In: A Formação Social da Mente. São Paulo: Martins Fontes, 19898. p. 106-118. 